\title{
Carbon storage and sequestration by urban forests in Shenyang, China
}

\author{
Changfu Liu ${ }^{\mathrm{a}, *}$, Xiaoma $\mathrm{Li}^{\mathrm{a}, \mathrm{b}}$ \\ a College of Forestry, Shenyang Agricultural University, No. 120 Dongling Road, Dongling District, Shenyang, Liaoning Province 110161, China \\ b State Key Laboratory of Urban and Regional Ecology, Research Center for Eco-Environmental Sciences, Chinese Academy of Sciences, Beijing 100085, China
}

\section{A R T I C L E I N F O}

\section{Keywords:}

Carbon density

Carbon emission

Carbon sequestration rate

Ecosystem service

Globe warming

Urban ecosystem

\begin{abstract}
A B S T R A C T
Urban forests can play an important role in mitigating the impacts of climate change by reducing atmospheric carbon dioxide $\left(\mathrm{CO}_{2}\right)$. Quantification of carbon (C) storage and sequestration by urban forests is critical for the assessment of the actual and potential role of urban forests in reducing atmospheric $\mathrm{CO}_{2}$. This paper provides a case study of the quantification of $C$ storage and sequestration by urban forests in Shenyang, a heavily industrialized city in northeastern China. The $C$ storage and sequestration were estimated by biomass equations, using field survey data and urban forests data derived from high-resolution QuickBird images. The benefits of $C$ storage and sequestration were estimated by monetary values, as well as the role of urban forests on offsetting $C$ emissions from fossil fuel combustion. The results showed that the urban forests in areas within the third-ring road of Shenyang stored 337,000 t C (RMB92.02 million, or $\$ 13.88$ million), with a C sequestration rate of $29,000 \mathrm{t} / \mathrm{yr}$ (RMB7.88 million, or $\$ 1.19$ million). The C stored by urban forests equaled to $3.02 \%$ of the annual C emissions from fossil fuel combustion, and $C$ sequestration could offset $0.26 \%$ of the annual $C$ emissions in Shenyang. In addition, our results indicated that the $C$ storage and sequestration rate varied among urban forest types with different species composition and age structure. These results can be used to help assess the actual and potential role of urban forests in reducing atmospheric $\mathrm{CO}_{2}$ in Shenyang. In addition, they provide insights for decision-makers and the public to better understand the role of urban forests, and make better management plans for urban forests.
\end{abstract}

Crown Copyright $\odot 2011$ Published by Elsevier GmbH. All rights reserved.

\section{Introduction}

Global warming, one of the frequently discussed topics, has evoked considerable social concerns (Crowley, 2000; Mann and Jones, 2003; Smith et al., 2007). Globally, the averaged surface air temperature increased $0.5^{\circ} \mathrm{C}$ in the 20th century. It is estimated that the global average air temperature would further increase by $1.5-4.5^{\circ} \mathrm{C}$ by the year 2100 (Houghton et al., 1996). The increase in air temperature was mainly due to the increasing emissions of greenhouse gases (Lashof and Ahuja, 1990), among which carbon dioxide $\left(\mathrm{CO}_{2}\right)$ is the most dominant one, accounting for three quarters of the total emissions (Olivier et al., 2005). Urban areas are already generally warmer than their surrounding rural environments due to high proportion of imperious surface and high levels of fossil fuel combustion (Lo et al., 1997; Doygun and Alphan, 2006; Weng and Yang, 2006). Therefore, impacts of climate change may be exacerbated in urban areas (Nowak and Crane, 2002).

Urban forests can play an important role in mitigating the impacts of climate change by reducing $\mathrm{CO}_{2}$ in urban areas (McHale et al., 2007; McPherson et al., 1999). Urban forests can reduce

\footnotetext{
* Corresponding author. Tel.: +86 13840256009.

E-mail address: liucf898@163.com (C. Liu).
}

the levels of atmospheric $\mathrm{CO}_{2}$ through sequestration and reducing $\mathrm{CO}_{2}$ emissions by conserving energy used for heating and cooling (McPherson et al., 1999; Nowak and Crane, 2002). Urban trees and shrubs can transform $\mathrm{CO}_{2}$ into above- and below ground biomass through photosynthesis, a process called carbon sequestration, and store carbon in the form of stems, branches, or roots (Nowak, 1994; McPherson, 1998; Jo, 2002; Nowak and Crane, 2002). Urban forest soils also store large amounts of organic $C$ before it releases into atmosphere (Jo, 2002; Pouyat et al., 2002, 2006). In addition, urban forests decrease building cooling demand by shading and evapotranspiration in the summer, and reduce heating demand through decreasing wind speed in the winter. The decrease in both cooling and heating demand reduces $\mathrm{C}$ emissions from fossil fuels combustion (McPherson et al., 1997; Akbari, 2002; McPherson and Simpson, 2003).

Quantification of $C$ storage and sequestration by urban forests can be used to assess the actual and potential role of urban forests in reducing atmospheric $\mathrm{CO}_{2}$ (Nowak and Crane, 2002). Studies on C storage and sequestration by urban forests have been mostly conducted in the United States (Rowntree and Nowak, 1991; Nowak, 1993, 1994; Jo and McPherson, 1995; McPherson et al., 1997, 1999; McPherson, 1998; Myeong et al., 2006; McHale et al., 2007, 2009; Escobedo et al., 2010). However, there has been an increasing interest in quantification of $C$ storage and sequestration by urban forests 


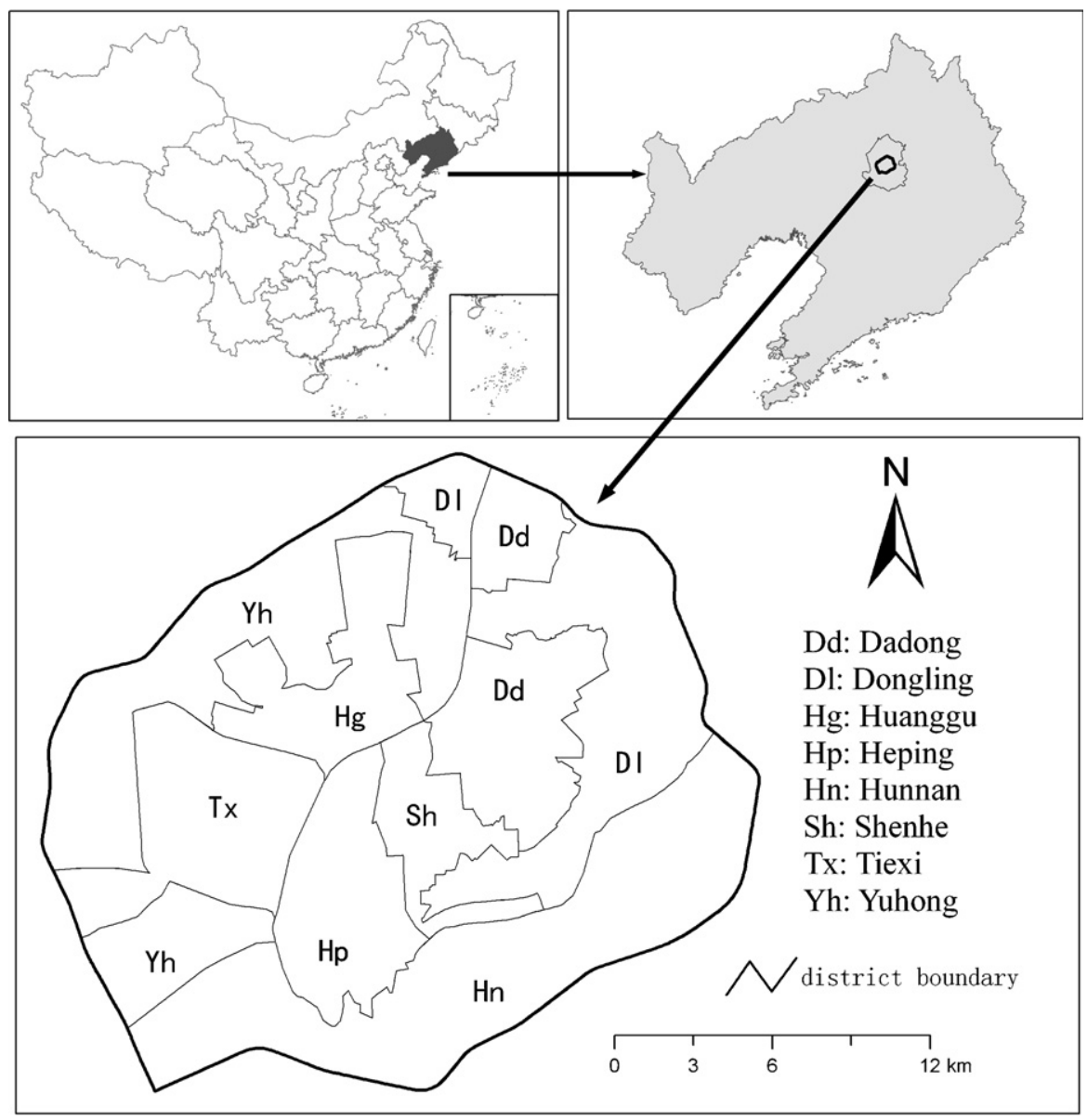

Fig. 1. The study area: areas within the third-ring road of Shenyang, China.

in both developing and developed countries (e.g., Brack, 2002; Jo, 2002; Yang et al., 2005; Gratani and Varone, 2006; Myeong et al., 2006; Stoffberg et al., 2010; Zhao et al., 2010). These studies greatly expand our understanding on the role of urban forests in $C$ storage and sequestration.

Shenyang is a heavily industrialized city in China, and was listed as one of the 10 most polluted cities in the world in the 1990s (He et al., 2003). A tree planting plan (TPP), among others, was developed in 2001 to improve the environment quality of the city. Approximately 19 million trees have been planted since the implementation of this plan. However, the effects of the trees on the city's environment improvement have not been well studied. This study focuses on the role of urban forests on $C$ storage and sequestration in Shenyang. Specifically, the objectives of this study were to: (1) quantify the $C$ storage and sequestration by urban forests and their monetary values in Shenyang; and (2) understand how the composition and structure of urban forests affect their functioning in $\mathrm{C}$ storage and sequestration. We quantified the $C$ storage and sequestration of urban forests based on biomass equations, using field survey data and urban forests data derived from high-resolution QuickBird image data.

\section{Study area}

This study focused on the areas within the third-ring road of Shenyang, with an area of $455 \mathrm{~km}^{2}$ (Fig. 1). Shenyang is the capital city of Liaoning Province in northeastern China. It has nine districts and four counties, with a total population of 7.04 million in 2006 (Shenyang Statistical Bureau, 2006). Our study area included Heping District, Shenhe District, Dadong District, Huanggu District,
Tiexi District, and part of Dongling District, Yuhong District, and Hunnan District (Fig. 1).

Shenyang is located in the transitional belt between Changbai Mountains and the alluvial plain of the Liaohe River (longitude: $122^{\circ} 21^{\prime}$ and $123^{\circ} 48^{\prime} \mathrm{E}$, latitude: $41^{\circ} 11^{\prime}$ and $\left.42^{\circ} 17^{\prime} \mathrm{N}\right)$. Eastern Shenyang is part of the Changbai Mountains, with an average elevation of about $150 \mathrm{~m}$, while the western Shenyang lies on the alluvial plain of the Liaohe River, with an average elevation of $30 \mathrm{~m}$. Shenyang has a monsoon-influenced humid continental climate, characterized by hot, humid summers and dry, cold winters. It has an annual average precipitation of $727.4 \mathrm{~mm}$, but with nearly half of the annual rainfall occurring in July and August. Its annual average evapotranspiration is $1407.7 \mathrm{~mm}$, with $603.6 \mathrm{~mm}$ occurred in the summer. Monthly mean temperatures range from $-12^{\circ} \mathrm{C}$ in January to $24.6^{\circ} \mathrm{C}$ in July, with an annual average of $7.9^{\circ} \mathrm{C}$. The accumulated temperature above $10^{\circ} \mathrm{C}$ is $3400^{\circ} \mathrm{C}$-h. The annual average non-frost period is about 150 days (He, 2004).

\section{Methods}

Satellite image processing and urban forest classification

QuickBird image data collected on August 19, 2006 were firstly georectified and reprojected in ERDAS 8.7. Then urban forests were extracted from the image by the visual interpretation method. Urban forests were further classified into five types based on their location, function, and management objectives (He et al., 2004). The area of each type of urban forests was calculated. These five types were: (1) Ecological and Public Welfare Forest (EF): trees planted as windbreaks, to prevent soil erosions, to prevent from flood, to 
Table 1

Number and area (mean \pm SD) of surveyed plots for each urban forest type.

\begin{tabular}{lcl}
\hline Urban forest type $^{\mathrm{a}}$ & $\begin{array}{l}\text { Number of } \\
\text { surveyed plots }\end{array}$ & $\begin{array}{l}\text { Average area of } \\
\text { plots (ha) }\end{array}$ \\
\hline $\mathrm{EF}$ & 30 & $0.25 \pm 0.15$ \\
$\mathrm{AF}$ & 46 & $0.20 \pm 0.09$ \\
$\mathrm{LF}$ & 74 & $0.23 \pm 0.14$ \\
$\mathrm{PF}$ & 14 & $0.33 \pm 0.14$ \\
$\mathrm{RF}$ & 49 & $0.31 \pm 0.21$ \\
Total & 213 & $0.25 \pm 0.16$
\end{tabular}

a EF, Ecological and Public Welfare Forest; AF, Attached Forest; LF, Landscape and Relaxation Forest; PF, Production and Management Forest; RF, Road Forest.

protect watersheds, levees, and to reduce pollutions or noises; (2) Attached Forest (AF): trees right next to buildings in school yards, campuses, hospitals, commercial and business districts, industrial areas and residential areas for landscape purposes; (3) Landscape and Relaxation Forest (LF): trees in the public parks, forest parks, historic sites, and scenic areas; (4) Production and Management Forest (PF): trees in the nurseries, orchards, plantations, and woodlands for commercial purposes; (5) Road Forest (RF): trees along railroads, highways, boulevards, roads, and streets.

\section{Field survey}

Two hundred and fifty plots were investigated in our study and the plot number of each urban forest type was determined according to the area of each forest type and its within-type variance of urban forest structure, including species diversity and DBH distribution of trees. At first, we applied the stratified sampling technique (Nowak et al., 2003) to allocate the plot number by using urban forest type as stratum. Secondly, the plot allocation scheme of the stratified sampling technique was modified to account for the within-type variance (species diversity and DBH distribution of trees) of each forest type according to our pre-investigation. Simultaneously, more than 10 plots were required for each urban forest type during our survey, which was recommended by Nowak et al. (2003). Finally the plot number of each forest type does not fully reflect the size of each forest type (Table 1). For example, Ecological and Public Welfare Forests cover relatively large area (46\% of the total urban forest area), however they have few species (poplar is the most dominated species) and similar forest age. So we only surveyed fewer sample plots for Ecological and Public Welfare Forests (Table 1).

In our study we firstly extracted different types of urban forests and applied the stratified sample method by using urban forest type as stratum. So the regularly shaped plot was not suitable in our study due to irregular shapes of different urban forest types. The shape of a plot in our study was determined by the crown boundary of the forests where the random point was located, instead of using a regular shape (e.g., a $400 \mathrm{~m}^{2}$ circle; Nowak et al., 2003). Consequently, the sample plots had irregular shapes, and varied in size (see Table 1 ). The size of the plots in our study ranged from
0.08 ha to $0.93 \mathrm{ha}$, larger than $400 \mathrm{~m}^{2}$ reported in many other studies (Nowak et al., 2003; Yang et al., 2005).

The field survey was conducted in September and October, 2006. For the 213 accessible sample plot, forest type was recorded. Within each plot, we recorded the species name, diameter at breast height (DBH), and health condition for each tree. Six types of health condition were included, based on the proportion of dead branches in the crown of a tree (Nowak et al., 2003; Yang et al., 2005). These included: (1) excellent, no obvious dead branches inside tree crown; (2) fair, <25\% of crown composed of dead branches; (3) poor, 26-50\%; (4) critical, 51-75\%; (5) dying, 76-99\%; and (6) dead, 100.

\section{Calculating carbon storage and sequestration}

Biomass equations were used to calculate the dry biomass of each surveyed tree (Chen, 1981, 1984; Chen and Guo, 1984; Li et al., 1985, 2007; Chen et al., 1986, 2007; Xu and Chen, 1987; Ma, 1989; Luo, 1996; Wang, 2006). The biomass of an individual tree is typically calculated based on either the DBH alone, or a combination of the DBH and tree height $(H)$. In this study, we used DBH only as this type of biomass equations does not require the measure of tree height, and thus can reduce uncertainty (Wang, 2006). We chose equations derived geographically near our study area, and in which the DBH range is applicable to trees surveyed in our study site. Usually more than one equation was used to obtain an averaged dry biomass (McHale et al., 2009). In cases only equations that were used to calculate above-ground biomass were available, the whole tree biomass was estimated based on the root-to-shoot ratio of 0.25 (Niklas and Enquist, 2002). When no equation could be found for an individual species, equations of species of the same genus were used to calculate an average. When no equations were found for a genus, a generalized equation from Wang (2006) was used. Table 2 listed the biomass equations used for the most common trees. Due to severe pruning, urban trees tend to have less above-ground biomass than that predicted by equations derived for natural forests (Nowak, 1994). In Shenyang, tree pruning was not common and mainly for old trees of AF and RF. Therefore, we gave a $20 \%$ biomass reduction only for trees with $\mathrm{DBH}$ greater than $30 \mathrm{~cm}$ (Nowak, 1994). The dry biomass was then converted to $\mathrm{C}$ by multiplying 0.5 (Nowak, 1994; Nowak and Crane, 2002). After that, $\mathrm{C}$ density (t/ha) was calculated for each plot.

Carbon sequestration was estimated as the difference of $C$ stored between year $y$ and year $y+1$, based on the annual growth rates of tree DBH. For deciduous species, C stored by foliage was subtracted, while for evergreen species, there was a $25 \%$ of foliage $C$ reduction by assuming 3-year leaf retention (Rowntree and Nowak, 1991; Jo, 2002). Annual growth rates of DBH for deciduous and evergreen trees with different DBH were determined based on the DBH measurements of 186 trees from 2003 to 2006 in Shenyang Arboretum, located in the urban center. The calculation of carbon sequestration was adjusted by tree health condition (Nowak and Crane, 2002). The adjusting factors of $1,1,0.76,0.42,0.15$, and 0 , were used for

Table 2

Dry biomass equations for the most common species and the generalized equation.

\begin{tabular}{|c|c|c|}
\hline Species & Biomass equation $^{\mathrm{a}}$ & References \\
\hline \multirow[t]{3}{*}{ Poplar (Populus spp.) } & $B=0.043 \times D^{2.84}$ & Xu and Chen (1987) \\
\hline & $B=0.073 \times D^{2.53}$ & Li et al. (2007) \\
\hline & $B_{\mathrm{s}}=0.036 \times D^{2.65}, B_{\mathrm{b}}=0.0086 \times D^{2.71}, B_{\mathrm{l}}=0.0014 \times D^{2.97}, B_{\mathrm{r}}=0.047 \times D^{2.19}$ & Luo (1996) \\
\hline Elm (Ulmus spp.) & $B_{\mathrm{s}}=0.043 \times D^{2.87}, B_{\mathrm{b}}=0.0074 \times D^{2.67}, B_{1}=0.0028 \times D^{2.50}$ & Chen and Guo (1984) \\
\hline Japanese pagoda tree (Sophora japonica (L.) Schott) & $B_{\mathrm{s}}=0.069 \times D^{2.54}, B_{\mathrm{b}}=0.068 \times D^{1.89}, B_{\mathrm{l}}=0.0015 \times D^{3.26}, B_{\mathrm{r}}=0.64 \times D^{1.01}$ & Li et al. (1985) \\
\hline \multirow[t]{2}{*}{ Chinese pine (Pinus tabulaeformis Carr.) } & $B_{\mathrm{s}}=0.11 \times D^{2.34}, B_{\mathrm{b}}=0.01 \times D^{2.58}, B_{\mathrm{l}}=0.0049 \times D^{2.48}, B_{\mathrm{r}}=0.64 \times D^{2.10}$ & Ma (1989) \\
\hline & $B_{\mathrm{s}}=0.03 \times D^{2.59}, B_{\mathrm{b}}=0.047 \times D^{1.95}, B_{\mathrm{l}}=0.021 \times D^{2.07}, B_{\mathrm{r}}=0.15 \times D^{1.44}$ & $\mathrm{Ma}(1989)$ \\
\hline Spruce (Picea spp.) & $B_{\mathrm{s}}=0.057 \times D^{2.48}, B_{\mathrm{b}}=0.012 \times D^{2.41}, B_{\mathrm{l}}=0.083 \times D^{2.37}, B_{\mathrm{r}}=0.0088 \times D^{2.54}$ & Chen and Guo (1984) \\
\hline Generalized equation & $B=0.11 \times D^{2.47}$ & Wang (2006) \\
\hline
\end{tabular}

${ }^{a} B$ is the biomass for the whole tree; $B_{\mathrm{s}}, B_{\mathrm{b}}, B_{\mathrm{l}}$, and $B_{\mathrm{r}}$ are biomass for stem, branch, leaf, and root, respectively; $D$ is the diameter at breast height. 
the types of health condition - excellent, fair, poor, critical, dying, and dead, respectively (Nowak and Crane, 2002). Followed by the calculation of $C$ sequestration, $C$ sequestration rate $(t / h a / y r)$ was calculated for each plot.

Estimating $C$ storage and sequestration by urban forests for the entire study area

The equations below were used to calculate the $C$ storage and sequestration and number of trees for our study area, based on the $C$ density, $C$ sequestration rate, and tree density calculated from the sampled plots.

$P=\sum_{i=1}^{5} P t_{i}$

$P t_{i}=X_{i} \times A_{i}$

$X_{i}=\frac{\sum_{j=1}^{n} X_{i j}}{n}$

$X_{i j}$ is the C density, C sequestration rate, or tree density for the $i$ th stratum and the $j$ th sample plot. $n$ is plot number for the $i$ th stratum. $X_{i}$ is the averaged C density, C sequestration rate, or tree density for the $i$ th stratum. $A_{i}$ is the area of the $i$ th stratum. $P t_{i}$ is the value of estimation for the $i$ th stratum. $P$ is the value of the estimation for the study area.

The following formulas were used to calculate the variance of the estimation of the $C$ storage and sequestration and number of trees:

$V A R=\sum_{i=1}^{5} V A R t_{i}$

$V A R t_{i}=V A R_{i} \times A_{i}$

$V A R_{i}=\frac{s_{i}}{\sqrt{n}}$

$s_{i}=\sqrt{\frac{\left(1-f_{i}\right) \times \sum_{j=1}^{n}\left(X_{i j}-X_{i}\right)^{2}}{n-1}}$

$S_{i}$ and $V A R_{i}$ are the standard deviation and variance of the C density, $C$ sequestration rate, or tree density for the $i$ th stratum, respectively. $f_{i}$ is the proportion of area sampled for the ith stratum. VAR $t_{i}$ is the variance of the estimation for the ith stratum. VAR is the variance of the estimation for the study area.

\section{Estimating benefits of urban forests in carbon storage and sequestration}

Monetary value of $\mathrm{C}$ storage and sequestration provided by urban trees in Shenyang was evaluated based on afforestation cost. The afforestation cost is typically estimated as the total afforestation invests divided by the carbon sequestered by the forests (Xue and Tisdell, 2001). We adopted the widely used price (i.e., RMB273.3/t C or $\$ 41 / \mathrm{t} \mathrm{C}$ ) to estimate the monetary value (Jim and Chen, 2009).

We also calculated the ratio of the total $C$ stored and sequestered by urban forests to the total carbon emissions from fossil fuels combustion. The annual average carbon emissions from the fossil fuels combustion in Shenyang from 2004 to 2006 were calculated based on statistical data (Shenyang Statistical Bureau, 2004, 2005, 2006). Different types of fossil fuels consumptions were first converted to standard coal based on the conversion coefficients (Table 3), and then multiplied by 2.277 to convert to $\mathrm{CO}_{2}$ (National Development and Reform Commission of China, 2007), and multiplied by 0.2727 to convert to $\mathrm{C}$.
Table 3

Annual fossil fuel usages for 2004, 2005, and 2006 in Shenyang and conversion coefficients from different types of fossil fuel to standard coal.

\begin{tabular}{|c|c|c|c|c|}
\hline \multirow[t]{2}{*}{ Fuel types } & \multicolumn{3}{|c|}{ Fossil fuel usage ${ }^{a}$} & \multirow[t]{2}{*}{ Coefficient ${ }^{b}$} \\
\hline & 2004 & 2005 & 2006 & \\
\hline Raw coal $\left(10^{6} \mathrm{t}\right)$ & 12.79 & 15.96 & 20.38 & 0.71 \\
\hline Cleaned coal $\left(10^{6} \mathrm{t}\right)$ & 0.67 & 1.07 & 1.67 & 0.9 \\
\hline Other washed coal $\left(10^{6} \mathrm{t}\right)$ & 0.27 & 0.27 & 0.29 & 0.29 \\
\hline Briquette $\left(10^{3} \mathrm{t}\right)$ & 12.77 & 14.14 & 36.18 & 0.6 \\
\hline Coke $\left(10^{3} \mathrm{t}\right)$ & 75.50 & 65.27 & 135 & 0.97 \\
\hline Coke oven gas $\left(10^{6} \mathrm{~m}^{3}\right)$ & 1.16 & 1.16 & 2.93 & 6.14 \\
\hline Other gas $\left(10^{6} \mathrm{~m}^{3}\right)$ & 47.96 & 29.07 & 21.15 & 3.57 \\
\hline Natural gas $\left(10^{6} \mathrm{~m}^{3}\right)$ & 34.39 & 58.13 & 85.67 & 12.14 \\
\hline Crude oil $\left(10^{6} \mathrm{t}\right)$ & 0.79 & 0.63 & 0.74 & 1.43 \\
\hline Gasoline $\left(10^{3} \mathrm{t}\right)$ & 45.48 & 38.85 & 82.02 & 1.47 \\
\hline Kerosene $\left(10^{3} \mathrm{t}\right)$ & 23.24 & 26.32 & 22.24 & 1.47 \\
\hline Diesel $\left(10^{3} \mathrm{t}\right)$ & 55.57 & 58.81 & 122 & 1.46 \\
\hline Fuel oil $\left(10^{6} \mathrm{t}\right)$ & 0.13 & 0.12 & 0.13 & 1.43 \\
\hline Liquefied petroleum gas $\left(10^{3} \mathrm{t}\right)$ & 28.47 & 104 & 12.65 & 1.71 \\
\hline Electricity $\left(10^{9} \mathrm{kWH}\right)$ & 5.81 & 7.30 & 8.69 & 0.40 \\
\hline Thermal $\left(10^{6} \mathrm{GJ}\right)$ & 17.74 & 16.93 & 10.38 & 0.034 \\
\hline
\end{tabular}

a Source: Shenyang Statistical Yearbook, 2004, 2005, and 2006.

b Coefficients from different fuel types to standard coal (State Statistical Bureau of China, 2006)

\section{Results}

\section{Urban forest structure}

There were $101 \mathrm{~km}^{2}$ of urban forests, or $22.28 \%$ of the total area of the study site. Ecological and Public Welfare Forest was the dominant forest type, accounting for nearly half of the area, followed by AF, LF, PF, and RF (Table 4).

Only 213 out of the 250 sample plots were surveyed because access to some plots was denied. Most of these unsurveyed plots were located in AF. Consequently, AF had relatively large standard errors in the estimation of $C$ storage and sequestration. We identified 120 tree species and 53 shrub species. Populus canadensis, Salix matsudana, and Ulmus pumila were the most common species (Table 5). There were approximately 5.76 million trees, with a density of 569 trees per ha. Production and Management Forest had the highest tree density, while RF had the lowest (Table 4). However, the majority of the trees were recently planted, with small $\mathrm{DBH}$. Nearly half of the trees had DBH smaller than $7.6 \mathrm{~cm}$, and $32 \%$ of trees had DBH between 7.7 and $15.2 \mathrm{~cm}$ (Fig. 2). The majority of the trees were in healthy condition, with $32 \%$ of the trees in excellent condition and $46 \%$ of the trees in fair condition (Fig. 3 ).

\section{Urban forest carbon storage and sequestration}

Carbon stored by urban forests was 337,000 t, among which EF and $\mathrm{AF}$ accounted for $41 \%$ and $34 \%$, respectively. The averaged $\mathrm{C}$ density was $33.22 \mathrm{t} / \mathrm{ha}$. Attached Forest had the highest $\mathrm{C}$ density (50.17 t/ha), followed by RF, LF, EF, and PF. The annual C sequestration by urban forests was $28,820 \mathrm{t}$. Similar to carbon storage,

Table 4

Urban forest area and tree number of different urban forest types $( \pm \mathrm{SE})$.

\begin{tabular}{lclc}
\hline $\begin{array}{l}\text { Urban forest } \\
\text { type }^{\mathrm{a}}\end{array}$ & Area $\left(\mathrm{km}^{2}\right)$ & $\begin{array}{l}\text { Tree density } \\
\text { (no./ha) }\end{array}$ & $\begin{array}{l}\text { Estimated tree } \\
\text { number }\left(10^{4}\right)\end{array}$ \\
\hline $\mathrm{EF}$ & 47.1 & $653 \pm 117$ & $307 \pm 54.88$ \\
$\mathrm{AF}$ & 22.7 & $375 \pm 55$ & $85.1 \pm 12.38$ \\
$\mathrm{LF}$ & 12.3 & $502 \pm 42$ & $61.9 \pm 5.17$ \\
$\mathrm{PF}$ & 10.9 & $905 \pm 133$ & $98.5 \pm 14.52$ \\
$\mathrm{RF}$ & 8.4 & $279 \pm 47$ & $23.4 \pm 3.96$ \\
Total & 101 & $569 \pm 90$ & $576 \pm 90.9$ \\
\hline
\end{tabular}

a EF, Ecological and Public Welfare Forest; AF, Attached Forest; LF, Landscape and Relaxation Forest; PF, Production and Management Forest; RF, Road Forest. 
Table 5

The five most common tree species of different urban forest types.

\begin{tabular}{|c|c|}
\hline $\begin{array}{l}\text { Urban forest } \\
\text { type }\end{array}$ & Dominate species with importance value form high to low \\
\hline $\mathrm{EF}$ & $\begin{array}{l}\text { Populus canadensis L., Robinia pseudoacacia L., Salix } \\
\text { matsudana Koidz., Ulmus pumila L., Populus alba var. } \\
\text { pyramidalis }\end{array}$ \\
\hline $\mathrm{AF}$ & $\begin{array}{l}\text { P. canadensis, U. pumila, S. matsudana, R. pseudoacacia, } \\
\text { Pinus tabulaeformis Carr. }\end{array}$ \\
\hline LF & $\begin{array}{l}\text { P. tabulaeformis, S. matsudana, } R \text {. pseudoacacia, } P \text {. } \\
\text { canadensis, Prunus davidiana (CarriŠre) Franch. }\end{array}$ \\
\hline $\mathrm{RF}$ & $\begin{array}{l}\text { P. tabulaeformis, S. matsudana, U. pumila, R. pseudoacacia, } P \text {. } \\
\text { tomentosa }\end{array}$ \\
\hline $\mathrm{PF}$ & $\begin{array}{l}\text { Ginkgo biloba L., P. tabulaeformis, Picea koraiensis Nakai, } \\
\text { Pyrus ussuriensis Lauche, U. pumila, U. pumilavar pendula }\end{array}$ \\
\hline Total & $\begin{array}{l}\text { P. canadensis, S. matsudana, U. pumila, } R \text {. pseudoacacia, } P \text {. } \\
\text { tabulaeformis }\end{array}$ \\
\hline
\end{tabular}

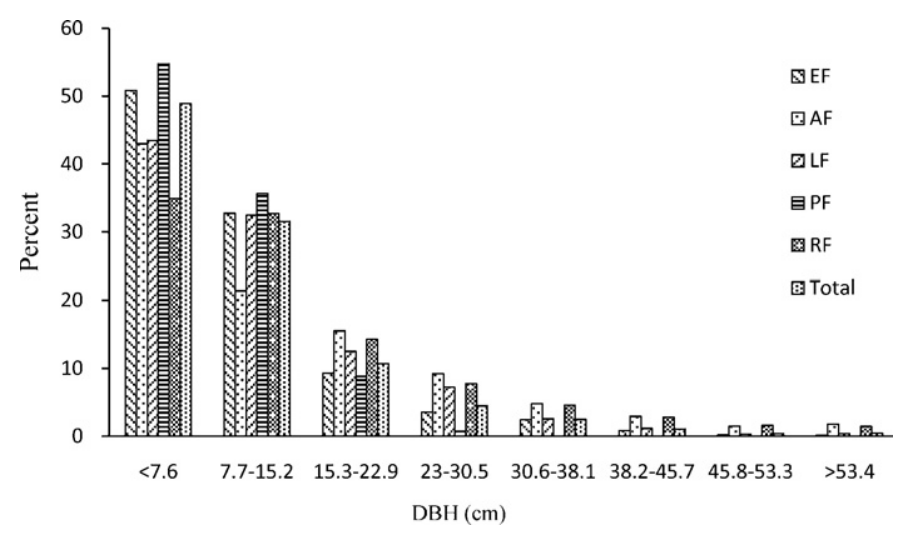

Fig. 2. Tree DBH distribution of different types of urban forests.

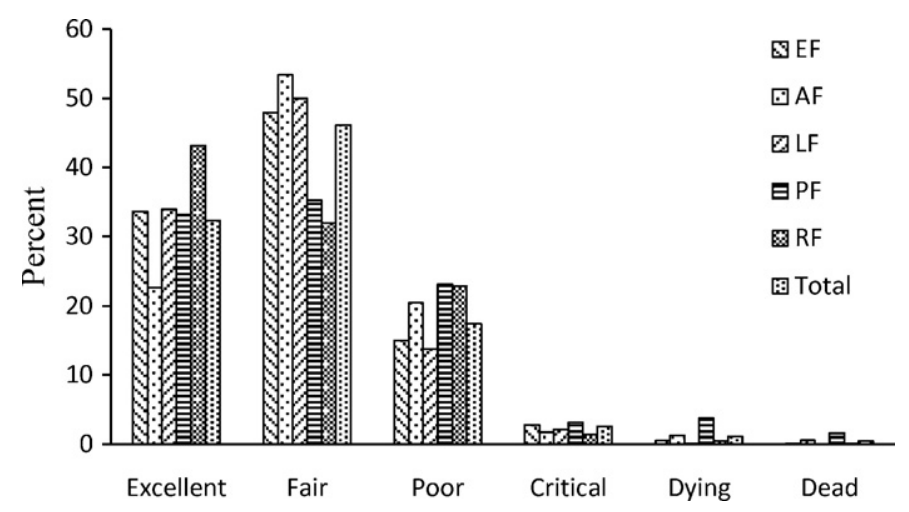

Fig. 3. Tree health condition of different types of urban forests.

the majority of the $\mathrm{C}$ was sequestered by $\mathrm{EF}$ and $\mathrm{AF}$ ( $40 \%$ and $38 \%$, respectively). The $\mathrm{C}$ sequestration rate was $2.84 \mathrm{t} / \mathrm{ha} / \mathrm{yr}$. For different types of urban forests, the $C$ sequestration rate ranged from $1.16 \mathrm{t} / \mathrm{ha} / \mathrm{yr}$ for PF to $4.78 \mathrm{t} / \mathrm{ha} / \mathrm{yr}$ for AF (Table 6).
Carbon storage and sequestration showed a very consistent spatial pattern with the distribution urban forests (Figs. 4 and 5). Generally, the urban center had lower $C$ storage and sequestration than the urban fringes. The northeastern part of the city had higher C storage and sequestration. Islands of high $C$ storage and sequestration occurred where urban parks located in the highly developed areas (Figs. 4 and 5).

\section{Benefits of carbon storage and sequestration}

Based on the afforestation cost, the $C$ stored by urban forests yielded a monetary value of RMB92.02 million ( $\$ 13.88$ million), and the value of annual $C$ sequestration by urban forests was RMB7.88 million (\$ 1.19 million). Annual average $C$ emissions from combustion of fossil fuels in Shenyang were 11.16 million tons from 2004 to 2006 (Table 3). About $0.26 \%$ of these $C$ emissions could be offset by $C$ sequestration of urban forests. In addition, the $C$ stored by urban forests equaled to $3.02 \%$ of the annual average $C$ emissions.

\section{Discussion}

Comparisons of urban forest carbon density and sequestration rate in Shenyang with other cities

The urban forests $C$ density of $33.22 \mathrm{t} /$ ha in Shenyang was higher than that in Hangzhou (30.25 t/ha), but lower than that in Beijing (43.70 t/ha), and within the range of many US cities (Table 7). The $C$ sequestration rate found in this study was much higher than those from previous studies (Table 7). These differences in C density and sequestration rate may be due to the different structure of the urban forests. Firstly, Shenyang had fewer big trees than cities such as Sacramento and Beijing. The ages of the trees, or the size of the trees (DBH) affect C storage and sequestration (Nowak, 1994). Generally, large healthy trees store and sequester more $C$ than small health trees (Nowak, 1994). Therefore, Shenyang had a lower $C$ density than these cities. Secondly, urban forests in Shenyang were dominated by fast-growth species (Table 5). This fast-growth species has relatively high rates of $\mathrm{C}$ sequestration, in turn leading to a higher C sequestration rate (Jo, 2002; Zhao et al., 2010). The high rate of $C$ sequestration of fast-growth species may also partly explain the phenomenon that urban forests in Shenyang had a smaller DBH but higher $C$ sequestration rate than that of Beijing. In addition, the higher $C$ sequestration rate of urban forests in Shenyang may be partly due to the relatively high tree density (Table 7).

\section{Comparisons of $C$ density and sequestration rate among different types of urban forests}

Attached Forest had the highest $C$ density and sequestration rate because it had more big trees than other types of urban forests (Fig. 2). While Road Forest had a similar proportion of big trees as Attached Forest (Fig. 2), it had a lower C density and sequestration rate than Attach Forest. This is because (1) Road Forest had a much

Table 6

Carbon density and total carbon storage and sequestration by urban forests ( \pm SE).

\begin{tabular}{|c|c|c|c|c|}
\hline \multirow[t]{2}{*}{ Types $^{\mathrm{a}}$} & \multicolumn{2}{|c|}{ Carbon density (t/ha) } & \multicolumn{2}{|l|}{ Total $\left(10^{3} \mathrm{t}\right)$} \\
\hline & Storage & Sequestration (/yr) & Storage & Sequestration (/yr) \\
\hline $\mathrm{EF}$ & $29.25 \pm 4.18$ & $2.45 \pm 0.32$ & $137.63 \pm 19.68$ & $11.55 \pm 1.50$ \\
\hline $\mathrm{AF}$ & $50.17 \pm 5.50$ & $4.78 \pm 1.54$ & $113.81 \pm 12.48$ & $10.85 \pm 3.49$ \\
\hline LF & $33.65 \pm 2.94$ & $2.47 \pm 0.25$ & $41.49 \pm 3.62$ & $3.05 \pm 0.31$ \\
\hline PF & $13.17 \pm 3.71$ & $1.16 \pm 0.28$ & $14.34 \pm 4.04$ & $1.26 \pm 0.31$ \\
\hline $\mathrm{RF}$ & $34.95 \pm 4.76$ & $2.51 \pm 0.28$ & $29.41 \pm 4.01$ & $2.11 \pm 0.24$ \\
\hline Total & $33.22 \pm 4.32$ & $2.84 \pm 0.58$ & $336.68 \pm 43.82$ & $28.82 \pm 5.84$ \\
\hline
\end{tabular}

\footnotetext{
a EF, Ecological and Public Welfare Forest; AF, Attached Forest; LF, Landscape and Relaxation Forest; PF, Production and Management Forest; RF, Road Forest.
} 


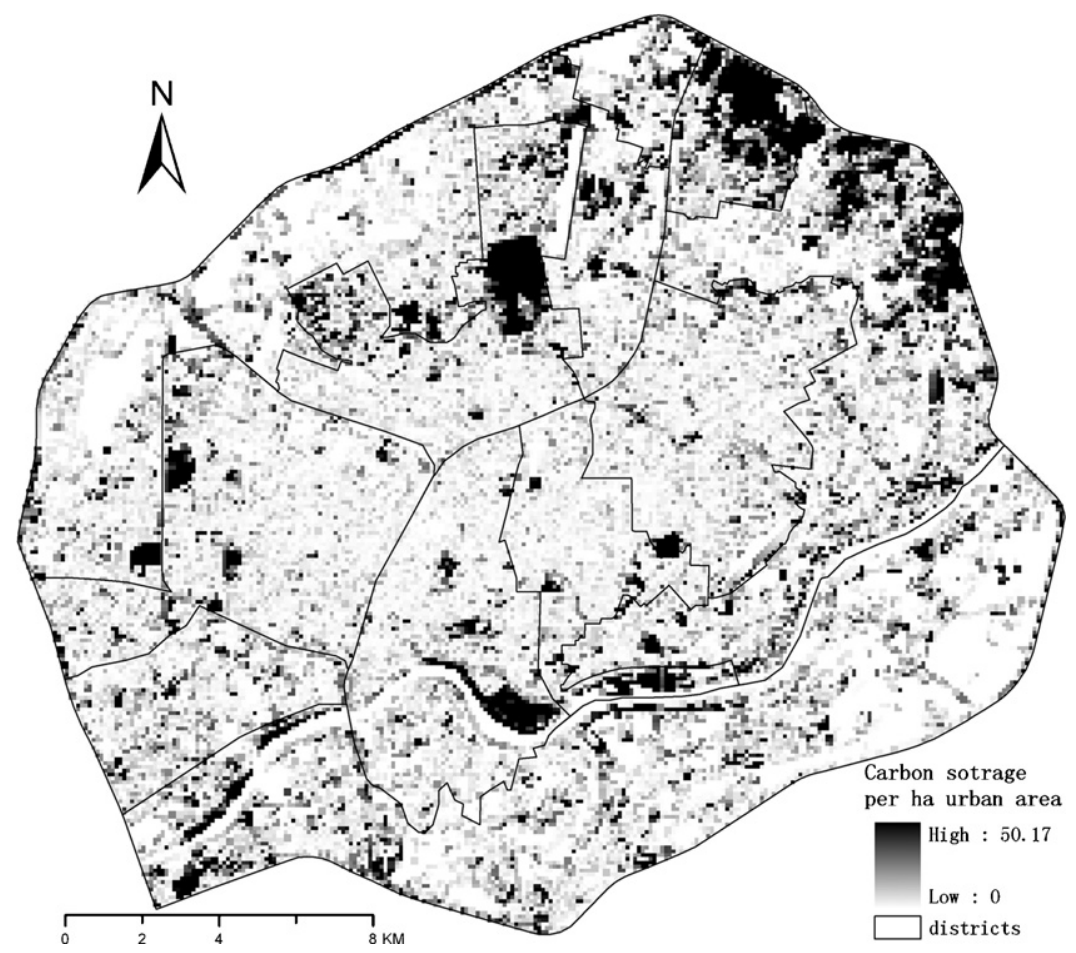

Fig. 4. Spatial distribution of the urban forest carbon storage.

lower tree density than Attached Forest (Table 4); and (2) P. tabulaeformis, a slow-growth species, was the dominant species in Road Forest (Table 5). With more big trees, Landscape and Relaxation Forest had a higher $\mathrm{C}$ density than Ecological and Public Welfare Forest (Table 4). However, as Landscape and Relaxation Forest had more slow-growth trees, it had a similar $\mathrm{C}$ sequestration rate with Ecological and Public Welfare Forest. Production and Management Forest had the lowest $C$ density and sequestration rate because it was mostly composed by small trees, even though it had the highest tree density.

Benefits of carbon storage and sequestration by urban forests

Quantifying the benefits of $C$ storage and sequestration by urban forests may help the decision-makers and the public better understand the role of urban forests in reducing atmospheric $\mathrm{CO}_{2}$, and

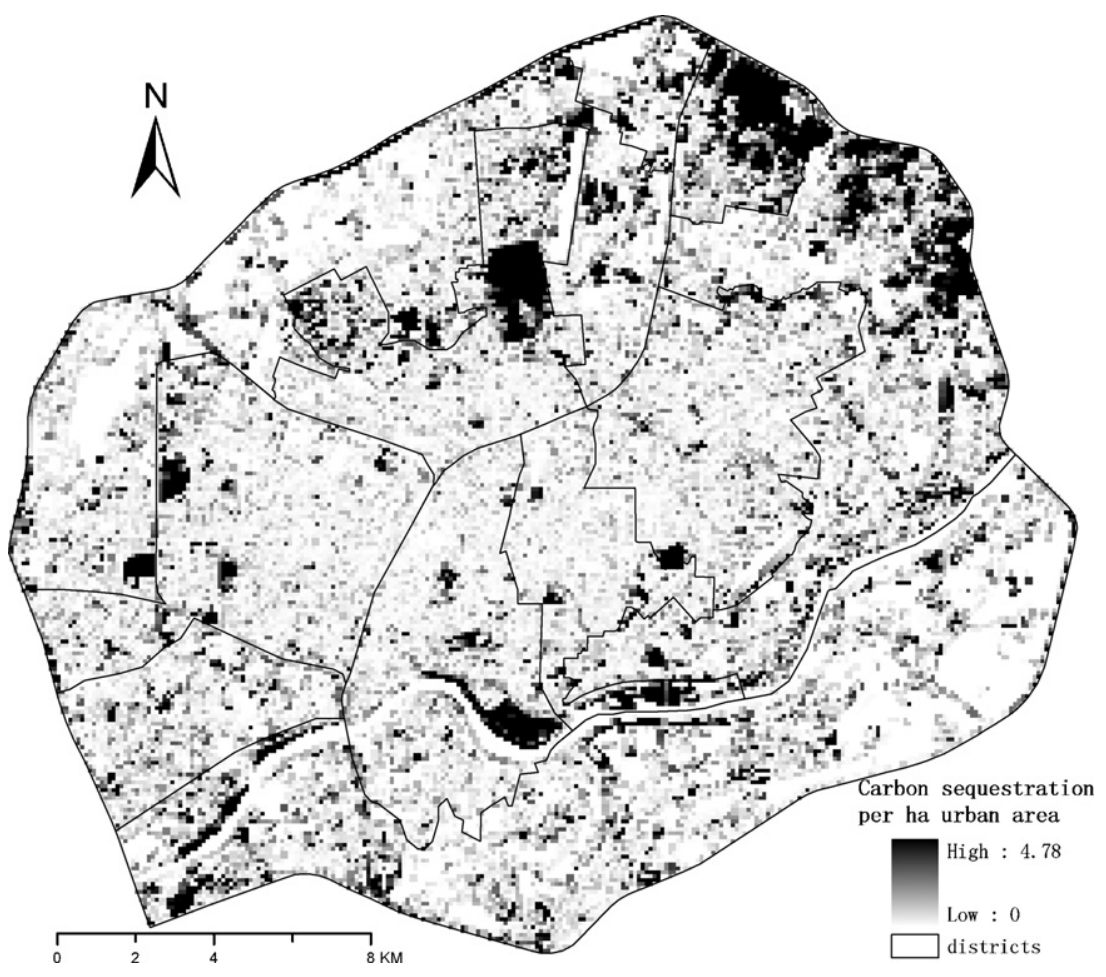

Fig. 5. Spatial distribution of the urban forest carbon sequestration. 
Table 7

Urban forest $C$ density and sequestration capacity in different cities $( \pm \mathrm{SE})$.

\begin{tabular}{|c|c|c|c|c|}
\hline City & $\mathrm{C}$ density ( $\mathrm{t} / \mathrm{ha})$ & $\mathrm{C}$ sequestration (t/ha/yr) & Tree density (no/ha) & References \\
\hline Shenyang, China & $33.22 \pm 4.32$ & $2.84 \pm 0.58$ & $569 \pm 90$ & This study \\
\hline Beijing, China & $43.70 \pm 6.65$ & $2.22 \pm 0.25$ & $465 \pm 59$ & Yang et al. (2005) \\
\hline Hangzhou, China & 30.25 & 1.66 & - & Zhao et al. (2010) \\
\hline Atlanta, US & $35.74 \pm 2.69$ & $1.23 \pm 0.08$ & $276 \pm 22$ & Nowak and Crane (2002) \\
\hline Baltimore, US & $25.28 \pm 3.16$ & $0.71 \pm 0.08$ & $136 \pm 29$ & Nowak and Crane (2002) \\
\hline Jersey city, US & $5.02 \pm 0.68$ & $0.21 \pm 0.02$ & $36 \pm 6$ & Nowak and Crane (2002) \\
\hline Sacramento, US & $46.91 \pm 22.64$ & $0.85 \pm 0.19$ & $73 \pm 15$ & McPherson (1998) \\
\hline
\end{tabular}

make better management plans (McHale et al., 2007; Jim and Chen, 2008). Two methods have been typically used to quantify the benefits of $C$ storage and sequestration by urban forests: (1) calculating the monetary value using a C fixation price (e.g., McPherson, 1998; Nowak and Crane, 2002); and (2) estimating the effects of $C$ storage and sequestration by urban forests in offsetting $C$ emissions from combustion of fossil fuels (e.g., Escobedo et al., 2010; Jo, 2002; Zhao et al., 2010). We used both methods in our study as they are complementary, and thus can provide different perspectives of the benefits provided by urban forests. For the first method, there is no standard global price. Different prices have been applied in different cities (e.g., McPherson, 1998; Nowak and Crane, 2002). Therefore, it is difficult to use this method for comparisons among different cities. In this study, we chose the afforestation cost price to estimate the monetary because it has been widely used for natural forests in China (Xue and Tisdell, 2001; Dong et al., 2007). The second method has also been widely used (e.g., Escobedo et al., 2010; Jo, 2002; Zhao et al., 2010). One of the advantages of this method is that comparisons among different cities are plausible. However, cautions should be taken when conducting comparisons. For example, in our study, when calculating the amounts of $C$ stored and sequestered by urban forests, we only considered the urban forests within the third-ring road. The $C$ emissions, however, were for the entire Shenyang. Consequently, the benefits were largely underestimated.

\section{Management implications}

Our results showed that the $C$ density and sequestration rate of the urban forests in Shenyang were relatively high compared with other cities. However, they were much lower than that of the natural forests. For example, $C$ density of natural forests in northeastern China was 50-70 t/ha (Fang et al., 2001). These results may suggest that there are still great potentials to increase the capacity of the $\mathrm{C}$ storage and sequestration by urban forests in Shenyang. This has some important management implications. Firstly, there are still great potentials to increase the total area of urban forests in Shenyang. Currently, the urban forest cover is only $22.28 \%$. The climatic and physiographic condition of Shenyang is very suitable for tree growth. More trees can be planted and more $C$ can be stored and sequestered. In particular, planting trees of native species with fast growth rates may further improve the capacity of $C$ storage and sequestration of urban forests.

Our results indicated that the majority of the urban trees were in their early stage, suggesting an increasing $C$ storage density and sequestration rate with the growth of those trees (Nowak, 1994; Yang et al., 2005). However, these young trees in urban areas require careful management and maintenance. In addition, many of the patches of urban forests have a single layer of tree species, with similar ages. Therefore, there are great potentials to enhance the capacity of these urban forests in C storage and sequestration by optimizing their structure, such as the creation of multiple layers of trees, shrubs and grass, and a mixture of trees with different ages.

\section{Conclusions}

Urban forests can play an important role in mitigating the impacts of climate change by reducing atmospheric $\mathrm{CO}_{2}$ in urban areas. Quantification of $\mathrm{C}$ storage and sequestration by urban forests is critical for the assessment of the actual and potential role of urban forests in reducing atmospheric $\mathrm{CO}_{2}$. This research provides a case study of the quantification of $\mathrm{C}$ storage and sequestration by urban forests in Shenyang, a heavily industrialized city in northeastern China. Based on field data and urban forests data derived from high-resolution QuickBird image, it is estimated that urban trees in areas within the third-ring road of Shenyang stored 337,000 t of carbon (RMB92.02 million, or $\$ 13.88$ million), with a C sequestration rate of 29,000 t/yr (RMB7.88 million, or $\$ 1.19$ million). The $C$ stored by urban forests equaled to $3.02 \%$ of the annual $\mathrm{C}$ emissions from fossil fuel combustion, and $\mathrm{C}$ sequestration could offset $0.26 \%$ of the annual C emissions in Shenyang. In addition, our results indicated that the $C$ storage and sequestration rate varied among urban forest types with different species composition and age structure. These results can be used to help assess the actual and potential role of urban forests in reducing atmospheric $\mathrm{CO}_{2}$ in Shenyang. In addition, they provide insights for decision-makers and the public to better understand the role of urban forests in reducing atmospheric $\mathrm{CO}_{2}$, and make better management plans for urban forests.

\section{Acknowledgements}

This research was financially supported by the National Natural Science Foundation of China (30940013, 30600482). We sincerely thank Dr. Weiqi Zhou at the Department of Plant Sciences, University of California, Davis, and Dr. Hua Zheng at Research Center for Eco-Environmental Sciences, Chinese Academy of Sciences, who helped us improve the manuscript. Special thanks are given to Dr. Weiqi Zhou for editing the language. We also express our appreciation to the two reviewers for their constructive comments. Much gratitude is also given to Shenyang Arboretum for providing long-term tree DBH observation data and the students in Shenyang Agricultural University who participated in the field survey.

\section{References}

Akbari, $\mathrm{H} ., 2002$. Shade trees reduce building energy use and $\mathrm{CO}_{2}$ emissions from power plants. Environmental Pollution 116, 119-126.

Brack, C.L., 2002. Pollution mitigation and carbon sequestration by an urban forest. Environmental Pollution 116, 195-200.

Chen, C., 1981. Biomass allometric equations for cultivated Korean pine. Forestry Prospect and Design 2, 19-23 (in Chinese).

Chen, C., 1984. Studies on the production of Pinus armandii forests in the Qinling Mountains biomass and production of the arbor-layers in Pinus armandii forests. Journal of Northwest Forestry University 1,1-18 (in Chinese with English abstract).

Chen, C., Guo, X., 1984. Research on biomass for broad-leaved Korean pine forest. Forestry Prospect and Design 2, 10-19 (in Chinese).

Chen, L., Chen, Q., Bao, X., Ren, J., Miao, Y., Hu, Y., 1986. Studies on Chinese arborvitae (Platycladus orientalis) forest and its biomass in Beijing. Acta Phytoecologica Sinica 10, 17-25 (in Chinese with English abstract). 
Chen, T., Ma, Q., Feng, Z., Luo, X., 2007. Research on forest biomass in Xiaolong Mountains, Gansu Province. Journal of Beijing Forestry University 29, 31-36 (in Chinese with English abstract).

Crowley, T.J., 2000. Causes of climate change over the past 1000 years. Science 289, 270-277.

Dong, X., Gao, W., Chen, Y., Liang, W., 2007. Valuation of fragile agroecosystem services in the Loess region: a case study of Ansai county in China. Outlook on Agriculture 36, 247-253.

Doygun, H., Alphan, H., 2006. Monitoring urbanization of Iskenderun Turkey, and its negative implications. Environmental Monitoring and Assessment 114, $145-155$.

Escobedo, F., Varela, S., Zhao, M., Wagner, J.E., Zipperer, W., 2010. Analyzing the efficacy of subtropical urban forests in offsetting carbon emissions from cities. Environmental Science and Policy 13, 362-372.

Fang, J., Chen, A., Peng, C., Zhao, S., Ci, L., 2001. Changes in forest biomass carbon storage in China between 1949 and 1998. Science 292, 2320-2322.

Gratani, L., Varone, L., 2006. Carbon sequestration by Quercus ilex L. and Quercus pubescens Willd and their contribution to decreasing air temperature in Rome. Urban Ecosystems 9, 27-37.

He, X., 2004. Shenyang Urban Forest. Science Press, Beijing (in Chinese)

He, K., Huo, H., Zhang, Q., 2003. Urban air pollution in China: current status, characteristics, and progress. Annual Review of Energy and the Environment 27, 397-431.

He, X., Liu, C., Chen, W., Guan, Z., Zhao, G., 2004. Discussion on urban forest classification. Chinese Journal of Ecology 23, 175-178 (in Chinese with English abstract).

Houghton, J.T., Meira Filho, L.G., Callender, B.A., Harris, N., Kattenberg, A., Maskell, K., (Eds.), 1996. Climate Change 1995: The Science of Climate Change. Cambridge.

Jim, C.Y., Chen, W.Y., 2008. Assessing the ecosystem service of air pollutant removal by urban trees in Guangzhou (China). Journal of Environmental Management $88,665-676$

Jim, C.Y., Chen, W.Y., 2009. Ecosystem services and valuation of urban forests in China. Cities 26, 187-194.

Jo, H.K., 2002. Impacts of urban greenspace on offsetting carbon emissions for middle Korea. Journal of Environmental Management 64, 115-126.

Jo, H.K., McPherson, G.E., 1995. Carbon storage and flux in urban residential greenspace. Journal of Environmental Management 45, 109-133.

Lashof, D.A., Ahuja, D.R., 1990. Relative contributions of greenhouse gas emissions to global warming. Nature 344, 529-531.

Li, J., Li, C., Peng, S., 2007. Study on the biomass expansion factor of poplar plantation. Journal of Nanjing Forestry University 31, 37-40 (in Chinese with English abstract).

Li, Z., Zhang, Y., Zhang, K., Ma, H., Jiang, Z., Tong, G., Zhu, T., Li, Y., Wang, J., Li, X., Zhao, C., 1985. Studies on the dry-matter production and distribution of black locust (Robinia pseudoacia) plantations in eastern Henan Province. Journal of Henan Agricultural University 19, 382-392 (in Chinese with English abstract).

Lo, C.P., Quattrochi, D.A., Luvall, J.C., 1997. Application of high-resolution thermal infrared remote sensing and GIS to assess the urban heat island effect. International Journal of Remote Sensing 18, 287-304.

Luo, T., 1996. Patterns of net primary productivity for Chinese major forest types and their mathematical models. PhD Dissertation. Chinese Academy of Sciences, Beijing, pp. 125-130.

Ma, Y., 1989. A study on the biomass of Chinese pine forest. Journal of Beijing Forestry University 11,1-10 (in Chinese with English abstract).

Mann, M.E., Jones, P.D., 2003. Global surface temperatures over the past two millennia. Geophysical Research Letters 30, 1820

McHale, M.R., Burke, I.C., Lefsky, M.A., Peper, P.J., McPherson, E.G., 2009. Urban forest biomass estimates: is it important to use allometric relationships developed specifically for urban trees? Urban Ecosystems 12, 95-113.

McHale, M.R., McPherson, E.G., Burke, I.C., 2007. The potential of urban tree plantings to be cost effective in carbon credit markets. Urban Forestry and Urban Greening $6,49-60$.

McPherson, E.G., 1998. Atmospheric carbon dioxide reduction by Sacramento's urban forest. Journal of Arboriculture 24, 215-223.

McPherson, E.G., Nowak, D., Heisler, G., Grimmond, S., Souch, C., Grant, R., Rowntree, R., 1997. Quantifying urban forest structure, function, and value: the Chicago Urban Forest Climate Project. Urban Ecosystems 1, 49-61.
McPherson, E.G., Simpson, J.R., 2003. Potential energy savings in buildings by an urban tree planting programme in California. Urban Forestry and Urban Greening 2, 73-86.

McPherson, E.G., Simpson, J.R., Peper, P.J., Xiao, Q., 1999. Benefit-cost analysis of Modesto's municipal urban forest. Journal of Arboriculture 25 235-248.

Myeong, S., Nowak, D.J., Duggin, M.J., 2006. A temporal analysis of urban forest carbon storage using remote sensing. Remote Sensing of Environment 101, 277-282.

National Development and Reform Commission of China, 2007. China's National Climate Change Programme. Retrieved January 15th, 2009 from http://www.chinaembassy.org.sg/chn/xwdt/P020070611577558281561.pdf.

Niklas, K.J., Enquist, B.J., 2002. Canonical rules for plant organ biomass partitioning and annual allocation. American Journal of Botany 89, 812-819.

Nowak, D.J., 1993. Atmospheric carbon reduction by urban trees. Journal of Environmental Management 37, 207-217.

Nowak, D.J., 1994. Atmospheric carbon dioxide reduction by Chicago's urban forest. In: McPherson, E.G., Nowak, D.J., Rowntree, R.A. (Eds.), Chicago's Urban Forest Ecosystem: Results of the Chicago Urban Forest Climate Project. General Technical Report. Northeastern Forest Experiment Station-186 pp. 83-94.

Nowak, D.J., Crane, D.E., 2002. Carbon storage and sequestration by urban trees in the USA. Environmental Pollution 116, 381-389.

Nowak, D.J., Crane, D.E., Stevens, J.C., Hoehn, R.E., 2003. The Urban Forest Effects (UFORE) Model: Field Data Collection Manual. US Department of Agriculture Forest Service, Northeastern Research Station, Syracuse, NY.

Olivier, J., Van Aardenne, J., Dentener, F., Pagliari, V., Ganzeveld, L., Peters, J., 2005 Recent trends in global greenhouse gas emissions: regional trends 1970-2000 and spatial distribution of key sources in 2000. Environmental Sciences 2, 81-99.

Pouyat, R.V., Groffman, P., Yesilonis, I., Hernandez, L., 2002. Soil carbon pools and fluxes in urban ecosystems. Environmental Pollution 116, 107-118.

Pouyat, R.V., Yesilonis, I.D., Nowak, D.J., 2006. Carbon storage by urban soils in the United States. Journal of Environmental Quality 35, 1566-1575.

Rowntree, R.A., Nowak, D.J., 1991. Quantifying the role of urban forests in removing atmospheric carbon dioxide. Journal of Arboriculture 17, 269-275.

Shenyang Statistical Bureau, 2004. Shenyang Statistical Yearbook (2004). China Statistics Press, Beijing (in Chinese).

Shenyang Statistical Bureau, 2005. Shenyang Statistical Yearbook (2005). China Statistics Press, Beijing (in Chinese).

Shenyang Statistical Bureau, 2006. Shenyang Statistical Yearbook (2006). China Statistics Press, Beijing (in Chinese).

Smith, D.M., Cusack, S., Colman, A.W., Folland, C.K., Harris, G.R., Murphy, J.M., 2007 Improved surface temperature prediction for the coming decade from a global climate model. Science 317, 796-799.

State Statistical Bureau of China, 2006. China Energy Statistical Yearbook. China Statistics Press, Beijing (in Chinese).

Stoffberg, G.H., van Rooyen, M.W., van der Linde, M.J., Groeneveld, H.T., 2010. Carbon sequestration estimates of indigenous street trees in the City of Tshwane South Africa. Urban Forestry and Urban Greening 9, 9-14.

Wang, C., 2006. Biomass allometric equations for 10 co-occurring tree species in Chinese temperate forests. Forest Ecology and Management 222, 9-16.

Weng, Q., Yang, S., 2006. Urban air pollution patterns, land use, and thermal landscape: an examination of the linkage using GIS. Environmental Monitoring and Assessment 117, 463-489.

$\mathrm{Xu}, \mathrm{X}$., Chen, Z., 1987. A preliminary study of the biomass of cultivated Chinese white poplar stands. Journal of Nanjing Forestry University 1,130-136 (in Chinese with English abstract)

Xue, D., Tisdell, C., 2001. Valuing ecological functions of biodiversity in Changbaishan Mountain Biosphere Reserve in Northeast China. Biodiversity and Conservation $10,467-481$.

Yang, J., McBride, J., Zhou, J., Sun, Z., 2005. The urban forest in Beijing and its role in air pollution reduction. Urban Forestry and Urban Greening 3, 65-78.

Zhao, M., Kong, Z., Escobedo, F.J., Gao, J., 2010. Impacts of urban forests on offsetting carbon emissions from industrial energy use in Hangzhou, China. Journal of Environmental Management 91, 807-813. 